\title{
Concurrent acute illness and comorbid conditions poorly predict antibiotic use in upper respiratory tract infections: a cross-sectional analysis
}

\author{
Ilene H Zuckerman ${ }^{\dagger 1}$, Eli N Perencevich ${ }^{\dagger 2,3}$ and Anthony D Harris*†3
}

Address: ${ }^{1}$ Department of Pharmaceutical Health Services Research, School of Pharmacy, University of Maryland, Baltimore, 220 Arch Street, Baltimore, Maryland, 21201, USA, 2VA Maryland Health Care System, Baltimore, Maryland, 21201, USA and ${ }^{3}$ Department of Epidemiology and Preventive Medicine, School of Medicine, University of Maryland, Baltimore, 100 North Greene Street Lower Level, Baltimore, Maryland, 21201, USA

Email: Ilene H Zuckerman - izuckerm@rx.umaryland.edu; Eli N Perencevich - eperence@epi.umaryland.edu; Anthony D Harris* - aharris@epi.umaryland.edu

* Corresponding author †Equal contributors

Published: 30 May 2007

BMC Infectious Diseases 2007, 7:47 doi:10.1/86/1471-2334-7-47
Received: 14 November 2006

Accepted: 30 May 2007

This article is available from: http://www.biomedcentral.com/I47/-2334/7/47

(C) 2007 Zuckerman et al; licensee BioMed Central Ltd.

This is an Open Access article distributed under the terms of the Creative Commons Attribution License (http://creativecommons.org/licenses/by/2.0), which permits unrestricted use, distribution, and reproduction in any medium, provided the original work is properly cited.

\begin{abstract}
Background: Inappropriate antibiotic use promotes resistance. Antibiotics are generally not indicated for upper respiratory infections (URIs). Our objectives were to describe patterns of URI treatment and to identify patient and provider factors associated with antibiotic use for URIs.

Methods: This study was a cross-sectional analysis of medical and pharmacy claims data from the Pennsylvania Medicaid fee-for-service program database. We identified Pennsylvania Medicaid recipients with a URI office visit over a one-year period. Our outcome variable was antibiotic use within seven days after the URI visit. Study variables included URI type and presence of concurrent acute illnesses and chronic conditions. We considered the associations of each study variable with antibiotic use in a logistic regression model, stratifying by age group and adjusting for confounders.

Results: Among 69,936 recipients with URI, 35,786 (5I.2\%) received an antibiotic. In all age groups, acute sinusitis, chronic sinusitis, otitis, URI type and season were associated with antibiotic use. Except for the oldest group, physician specialty and streptococcal pharyngitis were associated with antibiotic use. History of chronic conditions was not associated with antibiotic use in any age group. In all age groups, concurrent acute illnesses and history of chronic conditions had only had fair to poor ability to distinguish patients who received an antibiotic from patients who did not.
\end{abstract}

Conclusion: Antibiotic prevalence for URIs was high, indicating that potentially inappropriate antibiotic utilization is occurring. Our data suggest that demographic and clinical factors are associated with antibiotic use, but additional reasons remain unexplained. Insight regarding reasons for antibiotic prescribing is needed to develop interventions to address the growing problem of antibiotic resistance. 


\section{Background}

Upper respiratory tract infections (URIs) are one of the most frequent reasons patients see their physicians. [1] Antibiotics are generally not indicated for the treatment of URIs as the etiology is usually viral and antibiotics have no demonstrated benefit [1-5]. Recognition of this problem has resulted in numerous efforts to reduce the use of antibiotics in patients with URI, in large part to stem the recent increases in the prevalence of antibiotic resistant organisms[4,6,7]. Inappropriate use of antibiotics also leads to an unnecessarily high incidence of adverse drug reactions and additional costs with few benefits. Despite this knowledge, physicians continue to prescribe antibiotics in more than $45 \%$ of URI episodes [8-10].

Although other studies have explored factors associated with antibiotic use for URIs, few studies have examined the importance of comorbidity [11-14]. In fact, little information is available regarding the importance of comorbidity using administrative claims databases. The objectives of this study were to describe patterns of upper respiratory tract infection treatment and to identify patient factors and provider specialties associated with antibiotic use. In particular, since some comorbid conditions and comorbid acute illnesses may justify the use of antibiotics for URI episodes, we were interested in the predictive power of comorbid chronic conditions and comorbid acute illnesses for antibiotic use in URIs.

\section{Methods}

This study was a cross-sectional analysis of medical and pharmacy claims data from the Pennsylvania Medicaid fee-for-service program database. The study population comprised patients in the Pennsylvania Medicaid fee-forservice program (i.e., those not enrolled in a Medicaid health maintenance organization) with a diagnosis of URI. Patients were selected based on medical claims from June 1, 1999 through May 31, 2000, with an office visit coded with one of the following International Classification of Diseases,Ninth Revision, Clinical Modification [15] diagnostic codes indicating a respiratory tract infection: acute nasopharyngitis (460); acute pharyngitis, excluding streptococcal pharyngitis (462); acute URI of multiple or unspecified sites (465); acute laryngopharyngitis (465.0); acute URI, multiple sites (465.8); acute URI, unspecified site (465.9); acute bronchitis (466.0); influenza with other respiratory manifestations (487.1) and bronchitis not otherwise specified (490).

Since the unit of analysis was the patient and to avoid duplication of patients in the analysis, we randomly selected one URI episode for each patient during the study period to be designated the index URI episode. To be included in the study, patients must have been eligible for Medicaid for at least seven days before and after the serv- ice date of the index URI episode, to allow for the opportunity to observe antibiotic use and other acute conditions temporally related to the URI episode.

Patient demographic information was linked to medical and pharmacy claims files. Antibiotic prescription information within seven days after the index URI episode was extracted. The outcome variable was defined as evidence of antibiotic use (yes/no) on the same day as, or within seven days after the index URI episode date. The study variables of interest were (1) presence of concurrent acute illnesses (eight different variables indicating a diagnosis of otitis media, streptococcal pharyngitis, pneumonia, chronic sinusitis, acute sinusitis, urinary tract infection, cellulitis or bacteremia, within seven days before or seven days after the index URI episode); and (2) history of comorbid chronic conditions (defined as presence of one or more claims with a diagnosis of chronic bronchitis, immunodeficiency including HIV/AIDS, solid organ transplant or malignancy within one year prior to the index URI episode) that might impact a physician's decision to prescribe an antibiotic. In addition, analysis included evaluation of potential confounding factors associated with antibiotic use, including the patient's age, sex, race, county of residence (defined as one of six county clusters), season of the URI episode (winter, spring, summer or fall) and specialty of the office visit physician associated with the URI episode (defined as one of four primary specialty groups: family medicine/internal medicine/general practitioner; pediatrics; emergency medicine; all other specialties).

Analyses were conducted using SAS ${ }^{\circledast}$ PC version 8.0 (SAS Institute, Inc., Cary, North Carolina). Patient and provider characteristics were categorized and compared using the chi-square test. Logistic regression was used to estimate the association of each study variable with the probability of antibiotic use when adjusted for gender, race, physician specialty and season of the URI episode. Odds ratios (OR) and 95\% confidence intervals (CI) are reported. Since age modified the effect between antibiotic use and several of the other independent variables, we report separate regression models for four age groups ( 0 to 5 years, 6 to 21 years, 22 to 44 years and $\geq 45$ years). The $\mathrm{C}$ statistic, which estimates the area under the receiver-operating characteristic (ROC) curve, was used to evaluate the ability of the presence of any concurrent acute illness (aggregated into one dichotomous variable indicating the presence or absence of any of the concurrent acute illnesses) or history of chronic comorbid conditions to distinguish patients who received an antibiotic from patients who did not, while controlling for gender, race, physician specialty and season. Separate C statistics were calculated for each age group stratification. The $\mathrm{C}$ statistic reports values from 0.5 (indicating no predictive power) to 1.0 (indi- 
cating perfect prediction)[16] Values of less than 0.7 generally indicate poor predictive power.

This analysis was completed as part of an ongoing retrospective drug utilization review (DUR) program for the Pennsylvania Department of Public Welfare (DPW). The DUR program work plan was approved by the University of Maryland Institutional Review Board.

\section{Results \\ Study Population}

There were 69,936 unique Medicaid recipients with at least one episode of a URI during the identification period (Table 1). There were a total of 110,677 URI episodes; the number of episodes per patient ranged from 1 to 55, with a median and mode of 1 episode per patient. The mean age was 21.5 (SD 20.4) years, and the median age was 16 years. The study population was primarily female $(62.0 \%)$ and white $(83.9 \%)$. More than one third of the patients had a URI episode occurring during the winter season.

\section{Frequency and Characteristics of Antibiotic Treatment}

Among the 69,936 recipients included in the analysis, $35,786(51.2 \%)$ received an antibiotic on the same day as, or within seven days after their index URI episode. Among the patients who received an antibiotic, 27,656 (77.3\%) had an antibiotic prescription on the same day as the index URI episode and 34,091 (95.3\%) had an antibiotic prescription within three days of the index URI episode. Among those receiving an antibiotic, 33,900 (94.7\%) had only one antibiotic prescription; $1,815(5.1 \%)$ had two prescriptions, and $71(0.2 \%)$ had three or four antibiotic prescriptions on the same day or within seven days after the index URI episode. When excluding the 10,012 patients with a concurrent acute illness that may have justified an antibiotic, antibiotic prevalence was $47.8 \%$.

In the bivariate analysis, antibiotic use varied by age group ( $\mathrm{p}<0.0001$ ), with the lowest prevalence $(44.9 \%)$ in the youngest age group and the highest prevalence $(56.2 \%)$ in the oldest age group. The most frequently prescribed antibiotic was amoxicillin (36.9\% of antibiotic prescriptions), followed by azithromycin (19.6\%), clarithromycin (7.1\%), amoxicillin/clavulanate $(6.8 \%)$ and erythromycin $(5.1 \%)$.

\section{Factors Associated with Antibiotic Use}

The presence of any acute concurrent illness was significantly associated with antibiotic use, the strength of association was greatest in the youngest age group (OR 4.63, $95 \%$ CI 4.29, 5.00). (Table 2). Across all age groups except age $>45$ years, physician specialty was significantly associated with antibiotic use; family physicians and emergency room physicians were more likely to be the prescribing physician compared to other specialties and pediatricians (data not shown).
Table I: Characteristics of Medicaid patients with an upper respiratory tract infection (URI) episode $(n=69,936)$

\begin{tabular}{|c|c|}
\hline Characteristic & Number (\%) \\
\hline \multicolumn{2}{|l|}{ Age (years) } \\
\hline $0-5$ & $20,213(28.9 \%)$ \\
\hline $6-21$ & $21,843(31.2 \%)$ \\
\hline $22-44$ & $17,125(24.5 \%)$ \\
\hline 45 and older & $10,755(15.4 \%)$ \\
\hline \multicolumn{2}{|l|}{ Gender } \\
\hline Male & $26,602(38.0 \%)$ \\
\hline Female & $43,334(62.0 \%)$ \\
\hline \multicolumn{2}{|l|}{ Race } \\
\hline White & $58,663(83.9 \%)$ \\
\hline Nonwhite & $11,273(16.1 \%)$ \\
\hline \multicolumn{2}{|l|}{ Number of URI episodes in one year } \\
\hline 1 & $46,765(66.9 \%)$ \\
\hline 2 & 13,839 (19.8\%) \\
\hline 3 or more & $9,332(13.3 \%)$ \\
\hline \multicolumn{2}{|l|}{ Diagnosis of index URI episode } \\
\hline Acute bronchitis & $19,344(27.7 \%)$ \\
\hline Common cold & $1,818(2.6 \%)$ \\
\hline Influenza with respiratory symptoms & $1,682(2.4 \%)$ \\
\hline Acute URI, other sites or not specified & $47,092(67.3 \%)$ \\
\hline \multicolumn{2}{|l|}{ Presence of concurrent acute illnesses } \\
\hline Any acute condition & $10,012(14 \%)$ \\
\hline Otitis media & $5,505(8)$ \\
\hline Acute sinusitis & $2,373(3)$ \\
\hline Chronic sinusitis & $1,023(1)$ \\
\hline Pneumonia & $575(<1)$ \\
\hline Strep pharyngitis & $540(<1)$ \\
\hline Cellulitis & $117(<1)$ \\
\hline Urinary tract infection & $68(<1)$ \\
\hline Bacteremia & $13(<1)$ \\
\hline \multicolumn{2}{|l|}{ History of chronic comorbid conditions* } \\
\hline Yes & $1,763(2.5 \%)$ \\
\hline No & $68,173(97.5 \%)$ \\
\hline \multicolumn{2}{|l|}{ Physician specialty for index URI episode } \\
\hline $\begin{array}{l}\text { Family practice, general practice or internal } \\
\text { medicine }\end{array}$ & $28,320(40.5 \%)$ \\
\hline Pediatrics & $4,139(5.9 \%)$ \\
\hline Emergency medicine & $4,4 I I(6.3 \%)$ \\
\hline Other specialty & $33,066(47.3 \%)$ \\
\hline \multicolumn{2}{|l|}{ Season of index URI episode } \\
\hline Winter & $24,575(35.1 \%)$ \\
\hline Spring & $15,786(22.6 \%)$ \\
\hline Summer & $10,650(15.2 \%)$ \\
\hline Fall & $18,925(27.1 \%)$ \\
\hline
\end{tabular}

* One or more claims with a diagnosis of chronic bronchitis, immunodeficiency including HIVIAIDS, solid organ transplant or malignancy, one year prior to the index URI episode.

For each age group, the independent effects of each of the study variables of antibiotic use was analyzed using a multivariate logistic regression model, with antibiotic use (yes/no) as the outcome variable (Table 2). After controlling for gender, race, physician specialty and season in each age group, concurrent diagnoses of acute sinusitis, chronic sinusitis and otitis media were associated with antibiotic use, with the odds ratios for receiving an anti- 
Table 2: Adjusted odds ratios (OR) for antibiotic use in upper respiratory tract infections (URI) among Pennsylvania Medicaid fee-forservice recipients, June I, 1999 through May 31, 2000, by Age Group*

\begin{tabular}{|c|c|c|c|c|c|c|c|c|}
\hline & \multicolumn{8}{|c|}{ Odds Ratios for Antibiotic Use } \\
\hline & \multicolumn{2}{|c|}{ Age 0 - 5 years } & \multicolumn{2}{|c|}{ Age 6 - 2 I years } & \multicolumn{2}{|c|}{ Age $22-44$ years } & \multicolumn{2}{|c|}{ Age $\geq \mathbf{4 5}$ years } \\
\hline & OR & $95 \% \mathrm{Cl}$ & OR & $95 \% \mathrm{Cl}$ & OR & $95 \% \mathrm{Cl}$ & OR & $95 \% \mathrm{Cl}$ \\
\hline Any concurrent acute illness & 4.63 & $4.29-5.00$ & 2.83 & $2.58-3.10$ & 1.84 & $1.68-2.02$ & 1.73 & $1.5 \mathrm{I}-2.00$ \\
\hline Acute Sinusitis & 3.70 & $2.7 I-5.04$ & 2.80 & $2.33-3.36$ & 1.90 & $1.68-2.17$ & 2.17 & $1.75-2.68$ \\
\hline Bacteremia & 2.11 & $0.50-8.88$ & -- & -- & 0.21 & $0.02-1.90$ & -- & -- \\
\hline Cellulitis & 1.41 & $0.63-3.15$ & 1.38 & $0.61-3.14$ & 2.19 & $1.11-4.33$ & 0.90 & $0.44-1.84$ \\
\hline Chronic Sinusitis & 4.01 & $2.69-5.97$ & 2.98 & $2.29-3.88$ & 2.02 & $|.62-2.5|$ & 1.94 & I.39-2.73 \\
\hline Otitis media & 4.56 & $4.20-4.95$ & 2.88 & $2.53-3.28$ & 1.60 & $1.34-1.91$ & 1.70 & $|.2|-2.4 \mid$ \\
\hline Pneumonia & 1.71 & $1.27-2.29$ & 1.93 & $1.28-2.92$ & 1.18 & $0.84-1.64$ & 0.96 & $0.68-1.35$ \\
\hline Strep pharyngitis & 3.12 & $2.10-4.63$ & $|.6|$ & $1.26-2.06$ & 1.39 & $0.95-2.05$ & 0.76 & $0.3 I-1.84$ \\
\hline Urinary tract infection & 4.31 & $0.45-41.62$ & 3.02 & $1.00-9.14$ & 2.95 & I. $17-7.45$ & 0.73 & $0.31-1.73$ \\
\hline History of chronic conditions§ & 1.47 & $0.96-2.27$ & 1.06 & $0.75-|.5|$ & 1.10 & $0.93-1.29$ & I.II & $0.97-1.28$ \\
\hline \multicolumn{9}{|l|}{ URI Diagnosis } \\
\hline Influenza & $\mathrm{I}$ & Reference & I & reference & I & reference & 1 & reference \\
\hline Common cold & 1.64 & $1.20-2.25$ & 1.27 & $0.96-1.67$ & 1.42 & $1.07-1.88$ & 1.07 & $0.75-1.53$ \\
\hline Acute bronchitis & 4.83 & $3.63-6.42$ & 5.84 & $4.75-7.24$ & 4.28 & $3.52-5.20$ & 3.83 & $3.07-4.78$ \\
\hline Other sites or not specified & 1.74 & $1.32-2.30$ & 2.46 & $2.00-3.02$ & 2.54 & $2.09-3.08$ & 2.17 & I.73-2.7| \\
\hline
\end{tabular}

$\mathrm{Cl}$ denotes confidence interval.

--denotes OR cannot be calculated since there were no episodes of bacteremia.

*Adjusted for gender, race, physician specialty and season of URI. The probability of receiving an antibiotic at a visit was the dependent variable.

$\S$ Chronic conditions include chronic bronchitis, immunodeficiency including HIV/AIDS, solid organ transplant or malignancy.

biotic for each of theses acute illnesses highest in the youngest age group.

In children ages 0 to 5 years, a concurrent diagnosis of otitis media (OR 4.56, 95\% CI 4.20, 4.95), streptococcal pharyngitis (OR 3.12, 95\% CI 2.10, 4.63), chronic sinusitis (OR 4.01,95\% CI 2.93, 6.70), acute sinusitis (OR 3.85, $95 \%$ CI 2.69, 5.97) and pneumonia (OR 1.71, 95\% CI $1.27,2.29)$ increased the likelihood of receiving an antibiotic.

Patients aged 6 to 21 years were more likely to receive an antibiotic for a URI if they had a concurrent diagnosis of otitis media (OR 2.88, 95\% CI 2.53, 3.28), chronic sinusitis (OR 2.98,95\% CI 2.29, 3.88), acute sinusitis (OR 2.80, 95\% CI 2.33, 3.36) streptococcal pharyngitis (OR 1.61, $95 \%$ CI 1.26, 2.06) and pneumonia (OR 1.93, 95\% CI $1.28,2.92)$. Additionally, this age group was more likely to receive an antibiotic if there was a concurrent urinary tract infection (OR 3.02, 95\% CI 1.00, 9.14). In the 22 to 44 year old age group, four of the eight concurrent acute respiratory illnesses were significantly associated with antibiotic use for a URI [concurrent acute sinusitis (OR $1.90,95 \%$ CI 1.68-2.17), chronic sinusitis (OR 2.02, 95\% CI 1.62-2.51), cellulitis (OR 2.19, 95\% CI 1.11-4.33), otitis media (OR 1.60, 95\% CI 1.34-1.91)]. Concurrent urinary tract infection (OR 2.95, 95\% CI 1.17-7.45) was also associated with antibiotic use. Concurrent acute illnesses in the oldest group (age $\geq 45$ years) that were associated with antibiotic use included acute sinusitis (OR
$2.17,95 \%$ CI 1.75-2.68), chronic sinusitis (OR 1.94, 95\% CI 1.39-2.73), acute sinusitis (OR 2.17, 95\% CI 1.752.68) and otitis media (OR 1.70, 95\% CI 1.21-2.41). A history of chronic comorbid conditions (i.e., one or more claims with a diagnosis of chronic bronchitis, immunodeficiency including HIV/AIDS, solid organ transplant or malignancy, one year prior to the index URI episode) was not associated with antibiotic use in any of the age groups.

The $\mathrm{C}$ statistic (area under the ROC curve) was used to assess the ability of the presence of the regression models to discriminate patients who received antibiotics from those who did not. We report the C-statistics for the 'any acute condition' models (models corresponding to the first row of results in Table 2) and for the 'history of chronic conditions' models (models corresponding to the tenth row of results in Table 2). C statistics ranged from 0.54 (history of chronic comorbid conditions in the 22 to 44 year age group) to 0.67 (presence of concurrent acute illness in the 0 to 5 year age group), suggesting that these models have poor to fair predictive value.

\section{Discussion}

In the Pennsylvania Medicaid fee-for-service population during the study period, over one-half of recipients with an upper respiratory tract infection received an antibiotic on the same day as or within seven days after a physician visit for a URI. Even among those patients without a concurrent acute illness that may justify an antibiotic, antibiotic use was high (47.8\%). These findings are consistent 
with other similar analyses, which found $44 \%$ to $60 \%$ prevalence of antibiotic prescribing for colds or URIs $[8,9,17,18]$. The high prevalence indicates that potentially inappropriate antibiotic use is high and should be a target for antibiotic education and management to reduce excess use.

Antibiotic resistance is a worldwide public health issue, resulting in emerging antimicrobial resistance and costing $\$ 1.3$ billion in the United States in 1992[19]. Unfortunately, the extent of the problem is not fully realized since surveillance of drug-resistance is limited[20]. Evidence for a causal association between antimicrobial use and resistance is supported by ecological data (changes in use parallel changes in prevalence of resistance). Also, there is evidence of increased prevalence of resistance in nosocomial strains compared to community-acquired strains, association of prior antibiotic use with nosocomial outbreaks and association of increased antibiotic use with increased resistance rates[21,22].

To address prescribing factors, educational and administrative interventions have been proposed [23-31]. Administrative interventions are generally restrictive in nature and include prior authorization, formulary restriction, ordering forms and cycling. Educational interventions may include dissemination of susceptibility information, use of computer-based algorithms, and academic detailing. An understanding of the factors contributing to potentially inappropriate antibiotic use can help guide policy makers to design an effective educational or administrative intervention.

Our findings suggest that the presence of certain concurrent acute illnesses increase the likelihood of antibiotic use for a URI. It is possible those antibiotics were actually prescribed for these other acute conditions and that the URI was a coincidental diagnosis. Hence, it could be argued that for some patients the prescription of antibiotics may have been indicated.

However, antibiotic use was highly prevalent (47.8\%) even among those without a coincidental diagnosis. In the final regression models coincidental diagnoses only had fair to poor ability to distinguish patients who received an antibiotic from patients who did not, as indicated by the $\mathrm{C}$ statistics. Although the presence of illnesses such as otitis media or streptococcal pharyngitis was significantly associated with antibiotic use, they did not help to discriminate patients who received an antibiotic during a URI from those who did not. Thus, the reasons why physicians prescribe antibiotics for URIs is complex and is not fully explained by regression models of this study. Several reasons have been cited for inappropriate prescribing of antibiotics. These include patient expectation, [32-35] physicians' perception of patients' expectations, [32,3537] patients' lack of education, [35,38] and economic pressure[35,38]. Our findings suggest that more research is needed in understanding why antibiotics are being used for URIs in adults, as well as in children.

This paper explored predictive factors of antibiotic use for URI in an administrative database namely a Medicaid population. The concurrent presence of an acute illness such as cellulitis or UTI may explain the observed antibiotic prescription that was contemporaneous to a URI episode. In addition, we chose to explore the importance of comorbidity in predicting antibiotic use. For some chronic comorbid conditions, such as chronic malignancy or immunodeficiency, antibiotic use may be medically indicated for URIs. Thus, we chose a limited number of comorbid conditions, that we believe justified antibiotic use. Other studies have used a wider range of comorbid conditions that included diabetes, cardiovascular disease. These additional comorbid conditions may be important risk factors in that they increase antibiotic prescribing. However, we chose not to include these additional conditions because their presence generally does not justify antibiotic use.

One limitation of this study was that validation of the medical and prescription claims data against the primary data in the actual medical record was not possible due to limited resources. However, Medicaid prescription claims tend to be a reliable source of drug availability[39].

Reimbursement is linked to accurate billing, though the reliability of the diagnosis on the medical service claim is less certain since diagnosis generally does not influence reimbursement directly. This may result in misclassification of URI-related events due to incorrect data entry or wrong code assignment. For example, we included ICD-9CM code 490 (bronchitis not otherwise specified) in our definition of URI; this code may also include patients with COPD or acute exacerbation of chronic bronchitis. In addition, the severity of the URI or the actual indication for the antibiotic prescribed cannot be definitively determined from claims data. However, we did attempt to link the antibiotic to the URI episode temporally and control for other potential antibiotic indications in the analysis. Another limitation is that there may be misclassification of chronic disease history. Although we searched the administrative claims for evidence of chronic conditions for one year before the index URI episode, only $64 \%$ of subjects were eligible for an entire year. However, when we reran the 'history of chronic conditions' models for only those subjects with one year of eligibility prior to the URI episode, we obtained results to those in Table 2 (row $10)$, and nearly identical $C$ statistics to the reported models. 
Finally, these findings may not be generalizable to populations other than Medicaid, since Medicaid patients are differentiated by low economic status, source of care and other factors that may affect drug utilization.

\section{Conclusion}

This analysis suggests that demographic and clinical factors are associated with the prescription of an antibiotic for a URI, but much of the antibiotic use remains unexplained by acute illnesses and comorbid conditions. More insight into the reasons for antibiotic prescribing needs to be gained, which will lead to novel interventions that may hopefully curb the growing problem of antibiotic resistance.

\section{Competing interests}

The author(s) declare that they have no competing interests.

\section{Authors' contributions}

IZ, EP and AH have made substantial contributions to conception and design, data analysis and interpretation of data, have been involved in drafting the manuscript or revising it critically for important intellectual content and have given final approval of the version to be published

\section{Acknowledgements}

The authors acknowledge Drs. Van Doren Hsu and Linda Simoni-Wastila for reviewing the manuscript. The authors also acknowledge the staff of Pharmaceutical Research Computing, School of Pharmacy, University of Maryland, Baltimore, for assistance with data preparation. This project was supported in part by a contract with the Pennsylvania Department of Public Welfare.

\section{References}

I. Bauman KA: The family physician's reasonable approach to upper respiratory tract infection care for this century. Arch Fam Med 2000, 9(7):596-597.

2. Rosenstein NP William R.; Geber, Michael A.; Marcy, S. Michael; Schwartz, Benjamin; Dowell, Scott F: The common cold-principles of judicious use of antimicrobial agents. Pediatrics 1998, 101 (I) Supplement fo Pediatrics, Part 2 or 2:18I-184.

3. Evans AT, Husain S, Durairaj L, Sadowski LS, Charles-Damte M, Wang $Y$ : Azithromycin for acute bronchitis: a randomised, doubleblind, controlled trial. Lancet 2002, 359(93 |8): 1648-1654.

4. Gonzales R, Bartlett JG, Besser RE, Cooper RJ, Hickner JMM, Hoffman JR, Sande MA: Principles of appropriate antibiotic use for treatment of uncomplicated acute bronchitis: Background. Annals of Internal Medicine March 20, 200I, I34(6):52I-529.

5. Wenzel RP, Fowler AA 3rd: Clinical practice. Acute bronchitis. $N$ Engl J Med 2006, 355(20):2125-2I 30.

6. Hickner JM, Bartlett JG, Besser RE, Gonzales R, Hoffman JR, Sande $M A:$ Principles of appropriate antibiotic use for acute rhinosinusitis in adults: Background. Annals of Internal Medicine March 20, 200I, 134(6):498-505.

7. Gonzales R, Bartlett JG, Besser RE, Cooper RJ, Hickner JM, Hoffman $J R$, Sande MA: Principles of appropriate antibiotic use for treatment of acute respiratory tract infections in adults: background, specific aims, and methods. Ann Intern Med 200I, 134(6):479-486.

8. Nyquist AC, Gonzales R, Steiner JF, Sande MA: Antibiotic prescribing for children with colds, upper respiratory tract infections, and bronchitis. JAMA 1998, 279(II):875-877.
9. Mainous AG 3rd, Hueston WJ, Clark JR: Antibiotics and upper respiratory infection: do some folks think there is a cure for the common cold. J Fam Pract 1996, 42(4):357-36I.

10. Wang EE, Einarson TR, Kellner JD, Conly JM: Antibiotic prescribing for Canadian preschool children: evidence of overprescribing for viral respiratory infections. Clin Infect Dis 1999, 29(I): $155-160$.

II. Mainous AG 3rd, Hueston WJ, Love MM: Antibiotics for colds in children: who are the high prescribers? Arch Pediatr Adolesc Med 1998, I52(4):349-352.

12. Hall KK, Philbrick J, Nadkarni M: Evaluation and treatment of acute bronchitis at an academic teaching clinic. Am J Med Sci 2003, 325(I):7-9.

13. Piccirillo JF, Mager DE, Frisse ME, Brophy RH, Goggin A: Impact of first-line vs second-line antibiotics for the treatment of acute uncomplicated sinusitis. Jama 200 I, 286( I 5): I849-1856.

14. Steinman MA, Landefeld CS, Gonzales R: Predictors of broadspectrum antibiotic prescribing for acute respiratory tract infections in adult primary care. Jama 2003, 289(6):719-725.

15. Hurt AC, Schmidt KM, Aaron WS: St. Anthony's ICD-9-CM Code Book. Reston, Virginia , St. Anthoni's Publishing; 1998.

16. Hanley JA, McNeil BJ: The meaning and use of the area under a receiver operating characteristic (ROC) curve. Radiology 1982, I43(I):29-36.

17. Mainous AG 3rd, Hueston W]: The cost of antibiotics in treating upper respiratory tract infections in a medicaid population. Arch Fam Med 1998, 7(1):45-49.

18. Schwartz RH, Freij BJ, Ziai M, Sheridan MJ: Antimicrobial prescribing for acute purulent rhinitis in children: a survey of pediatricians and family practitioners. Pediatr Infect Dis J 1997, 16(2): $185-190$.

19. Harrison PF, Lederberg J: Antimicrobial Resistance: Issues and Options. Washington, D.C., National Academy Press; 1998.

20. Centers for Disease Control and Prevention: Active Bacterial Core surveillance. [http://www.cdc.gov/ncidod/dbmd/abcs/teamstart.htm\#Top].

21. McGowan JE Jr., Gerding DN: Does antibiotic restriction prevent resistance? New Horiz 1996, 4(3):370-376.

22. Safdar N, Maki DG: The commonality of risk factors for nosocomial colonization and infection with antimicrobial-resistant Staphylococcus aureus, Enterococcus, gram-negative bacilli, Clostridium difficile, and Candida. Ann Intern Med 2002, I36(II):834-844.

23. White AC Jr., Atmar RL, Wilson J, Cate TR, Stager CE, Greenberg SB: Effects of requiring prior authorization for selected antimicrobials: expenditures, susceptibilities, and clinical outcomes. Clin Infect Dis 1997, 25(2):230-239.

24. Gonzales R, Steiner JF, Lum A, Barrett PH Jr.: Decreasing antibiotic use in ambulatory practice: impact of a multidimensional intervention on the treatment of uncomplicated acute bronchitis in adults. JAMA 1999, 28I(16): $1512-1519$.

25. Mainous AG 3rd, Hueston WJ, Love MM, Evans ME, Finger R: An evaluation of statewide strategies to reduce antibiotic overuse. Family Medicine 2000, 32(I):22-29.

26. Schaffner W, Ray WA, Federspiel CF, Miller WO: Improving antibiotic prescribing in office practice. A controlled trial of three educational methods. JAMA 1983, 250(13): 1728-1732.

27. Finkelstein JA, Davis RL, Dowell SF, Metlay JP, Soumerai SB, Rifas-Shiman SL, Higham M, Miller Z, Miroshnik I, Pedan A, Platt R: Reducing antibiotic use in children: a randomized trial in 12 practices. Pediatrics 200I, 108(I): I-7.

28. Santoso B, Suryawati S, Prawaitasari JE: Small group intervention vs formal seminar for improving appropriate drug use. Soc Sci Med 1996, 42(8): I I63-II68.

29. Fraser GL, Stogsdill P, Dickens JD Jr., Wennberg DE, Smith RP Jr., Prato BS: Antibiotic optimization. An evaluation of patient safety and economic outcomes. Arch Intern Med 1997, 157(15):1689-1694.

30. Durbin WA Jr., Lapidas B, Goldmann DA: Improved antibiotic usage following introduction of a novel prescription system. Jama 1981, 246(16): 1796-1800.

3I. Perz JF, Craig AS, Coffey CS, Jorgensen DM, Mitchel E, Hall S, Schaffner W, Griffin MR: Changes in antibiotic prescribing for children after a community-wide campaign. JAMA 2002, 287(23):3103-3109. 
32. Britten $\mathrm{N}$, Ukoumunne $\mathrm{O}$ : The influence of patients' hopes of receiving a prescription on doctors' perceptions and the decision to prescribe: a questionnaire survey. BMJ 1997, 3I5(7I II): I506-I5I0.

33. Vinson DC, Lutz L): The effect of parental expectations on treatment of children with a cough: a report from ASPN. J Fam Pract 1993, 37(I):23-27.

34. Braun BL, Fowles JB: Characteristics and experiences of parents and adults who want antibiotics for cold symptoms. Arch Fam Med 2000, 9(7):589-595.

35. Belongia EA, Schwartz B: Strategies for promoting judicious use of antibiotics by doctors and patients. Bmj 1998, 3 I 7(7I59):668-67I.

36. Cockburn J, Pit S: Prescribing behaviour in clinical practice: patients' expectations and doctors' perceptions of patients' expectations--a questionnaire study. BMJ 1997, 3 I 5(7 | 07):520-523.

37. Mangione-Smith R, McGlynn EA, Elliott MN, Krogstad P, Brook RH: The relationship between perceived parental expectations and pediatrician antimicrobial prescribing behavior. Pediatrics 1999, I03(4 Pt I):7II-7I8.

38. Schwartz B, Mainous AG 3rd, Marcy SM: Why do physicians prescribe antibiotics for children with upper respiratory tract infections? JAMA 1998, 279(II):88I-882.

39. Lau HS, de Boer A, Beuning KS, Porsius A: Validation of pharmacy records in drug exposure assessment. J Clin Epidemiol 1997, 50(5):619-625.

\section{Pre-publication history}

The pre-publication history for this paper can be accessed here:

http://www.biomedcentral.com/1471-2334/7/47/prepub

Publish with Bio Med Central and every scientist can read your work free of charge

"BioMed Central will be the most significant development for disseminating the results of biomedical research in our lifetime. "

Sir Paul Nurse, Cancer Research UK

Your research papers will be:

- available free of charge to the entire biomedical community

- peer reviewed and published immediately upon acceptance

- cited in PubMed and archived on PubMed Central

- yours - you keep the copyright

Submit your manuscript here:

http://www.biomedcentral.com/info/publishing_adv.asp 